\title{
Design of Microcontroller Based Multilevel Inverter
}

\author{
Geetha Kiranmayee Sathi ${ }^{1}$, Ch.Santosh Kumar ${ }^{2}$ \\ ${ }^{1}$ Electrical Engineering and Renewable Energy Systems (Msc), University of Leeds. Leeds LS2 9JT, UK. \\ ${ }^{2}$ Department of Electrical and Electronics Engineering, Sridevi Women's Engineering College, Hyderabad, \\ India.
}

\begin{abstract}
The power electronics device which converts DC power to AC power at required output voltage and frequency level is known as inverter. Inverters can be broadly classified into single level inverter and multilevel inverter. Multilevel inverter as compared to single level inverters have advantages like minimum harmonic distortion, reduced EMI/RFI generation and can operate on several voltage levels. A multi-stage inverter is being utilized for multipurpose applications, such as active power filters, static var compensators and machine drives for sinusoidal and trapezoidal current applications. The drawbacks are the isolated power supplies required for each one of the stages of the multiconverter and it's also lot harder to build, more expensive, harder to control in software.This project aims at generation of PWM through the means of an AT89C52 microcontroller. The PWM signal thus generated is then used as pulses for the multilevel inverter.
\end{abstract}

Keywords: Microcontroller, PWM, stepped wave inverter, Multilevel inverter, Total Harmonic Distortion.

\section{INTRODUCTION}

Advances in microcontrollers in the last decade have revolutionized the electronics industry, making feasible the realization of sophisticated, "smart"and yet inexpensive, processing and control subsystems. Ac loads require constant or adjustable voltages at their input terminals. When such loads are fed by inverters, it's essential that output voltage of the inverters is so controlled as to fulfill the requirements of AC loads. This involves coping with the variation of DC input voltage, for voltage regulation of inverters and for the constant volts/frequency control requirement. There are various techniques to vary the inverter gain. The most efficient method of controlling the gain (and output voltage) is to incorporate pulse-width modulation (PWM) control within the inverters. The carrier based PWM schemes used for multilevel inverters is one of the most straight forward methods of describing voltage source modulation realized by the intersection of a modulating signal (Duty Cycle) with triangular carrier wavefroms.

\section{MICROCONTROLLER}

The AT89C52 is a low-power, high-performance CMOS 8-bit microcontroller with 8K bytes of in-system programmable Flash memory. The device is manufactured using Atmel's high-density non volatile memory technology and is compatible with the industry standard 80C51 instruction set and pin out. The on-chip Flash allows the program memory to be reprogrammed in-system or by a conventional non volatile memory programmer. By combining a versatile 8-bit CPU with in-system programmable Flash on a monolithic chip, the Atmel AT89C52 is a powerful microcontroller which provides a highly-flexible and cost-effective solution to many embedded control applications. The AT89C52 provides the following standard features: $8 \mathrm{~K}$ bytes of Flash, 256 bytes of RAM, 32 I/O lines, Watchdog timer, two data pointers, three 16-bit timer/counters, a six-vector two-level interrupt architecture, a full duplex serial port, on-chip oscillator, and clock circuitry. In addition, the AT89C52 is designed with static logic for operation down to zero frequency and supports two software selectable power saving modes.

\section{INVERTER}

A device that converts DC power into AC power at desired output voltage and frequency is called an Inverter. Phase controlled converters when operated in the inverter mode are called line commutated inverters. But line commutated inverters require at the output terminals an existing AC supply which is used for their commutation. This means that line commutated inverters can't function as isolated AC voltage sources or as variable frequency generators with DC power at the input. Therefore, voltage level, frequency and waveform on the AC side of the line commutated inverters can't be changed. On the other hand, force commutated inverters provide an independent AC output voltage of adjustable voltage and adjustable frequency and have therefore much wider application. 


\section{Multilevel Inverter}

A single-phase structure of an m-level cascaded inverter is illustrated in Figure 1. Each separate dc source (SDCS) is connected to a single-phase full-bridge, or H-bridge, inverter. Each inverter level can generate three different voltage outputs, $+\mathrm{Vdc}, 0$, and $-\mathrm{Vdc}$ by connecting the $\mathrm{dc}$ source to the ac output by different combinations of the four switches, S1, S2, S3, and S4. To obtain +Vdc, switches S1 and S4 are turned on, whereas $-\mathrm{Vdc}$ can be obtained by turning on switches S2 and S3. By turning on S1 and S2 or S3 and S4, the output voltage is 0 . The ac outputs of each of the different full-bridge inverter levels are connected in series such that the synthesized voltage waveform is the sum of the inverter outputs. The number of output phase voltage levels $\mathrm{m}$ in a cascade inverter is defined by $\mathrm{m}=2 \mathrm{~s}+1$, where $\mathrm{s}$ is the number of separate dc sources .

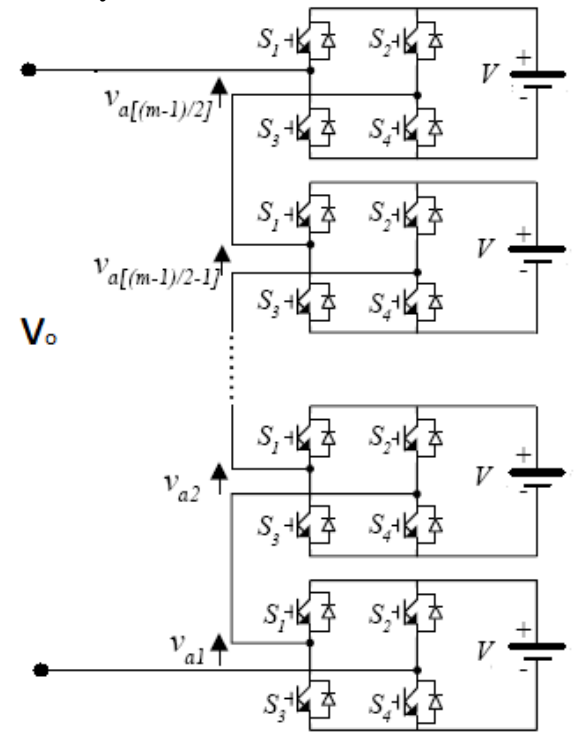

Fig .1 Single Phase Multilevel Inverter.

Table.1 Switching States of Cascaded Multilevel inverter.

\begin{tabular}{|c|c|c|c|c|c|c|c|c|}
\hline V0 & S1 & S2 & S3 & S4 & S1m & S2m & S3m & S4m \\
\hline V1 & 0 & 0 & 0 & 0 & 0 & 0 & 0 & 0 \\
\hline V2 & 0 & 1 & 0 & 0 & 0 & 1 & 1 & 0 \\
\hline V3 & 0 & 1 & 1 & 0 & 0 & 1 & 1 & 0 \\
\hline -V2 & 1 & 0 & 0 & 0 & 0 & 0 & 0 & 1 \\
\hline -V3 & 1 & 0 & 0 & 0 & 1 & 0 & 0 & 1 \\
\hline
\end{tabular}

The table 1 shows the switching states of multilevel inverter number 0 indicates switch is in off condition and number 1 indicates switch is in on condition and $\mathrm{S} 1 \mathrm{~m}$ to $\mathrm{S} 4 \mathrm{~m}$ indicates the switches correspond to $\mathrm{m}^{\text {th }}$ bridge.

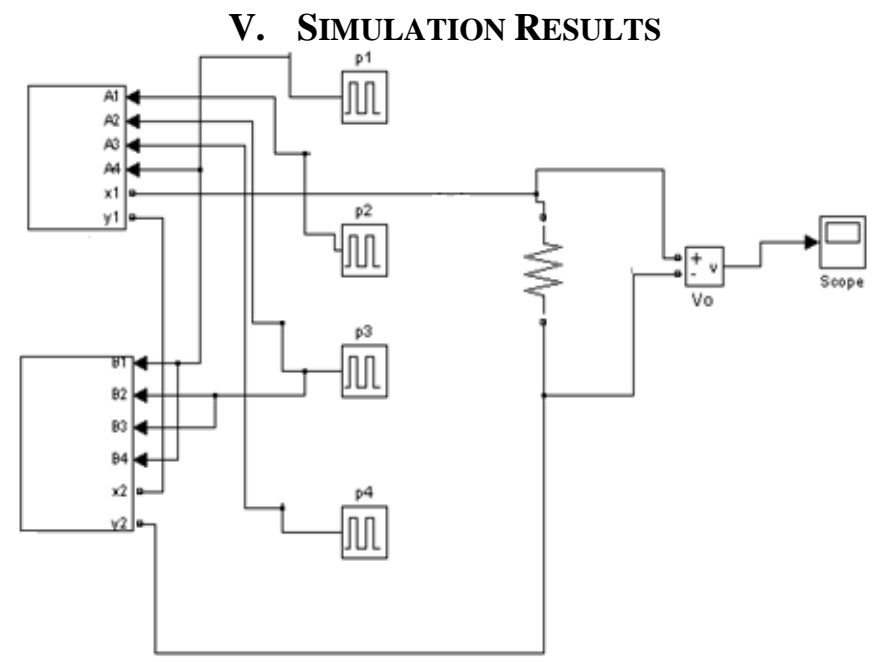

Fig.2Simulation circuit of Multilevel Inverter 
Simulation of Single Phase Cascaded Five Level Inverter is shown in figure 2.The output of the bridge inverter is connected to the resistive load. The cascaded inverter converts the DC voltage into AC voltage and the output voltage waveform is shown in figure 4 . The figure 3 shows the flow chart for triggering the switches.

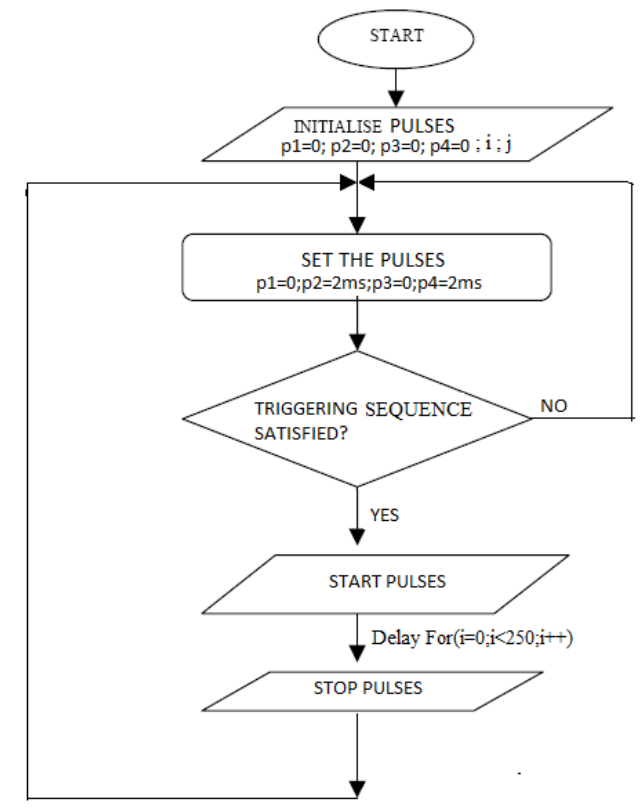

Fig.3 Flow Chart for triggering the Switches

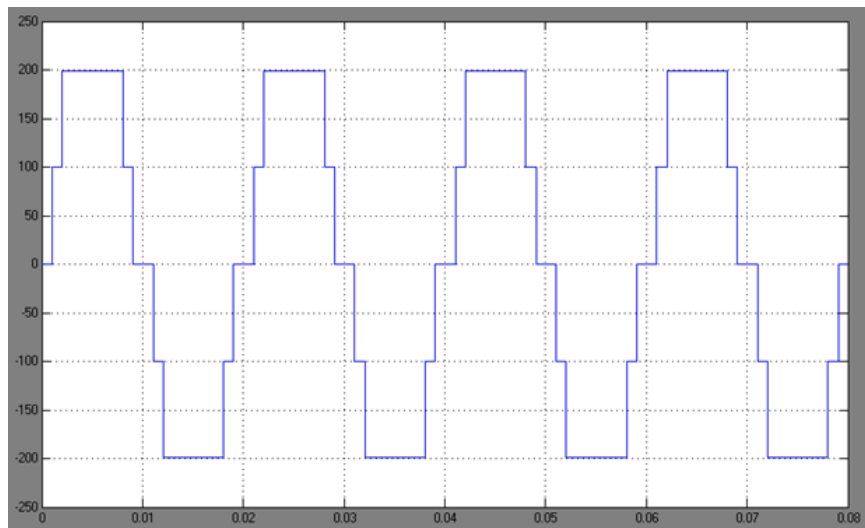

Fig.4 Single phase five level cascaded inverter output voltage

VI. EXPERIMENTAL RESULTS

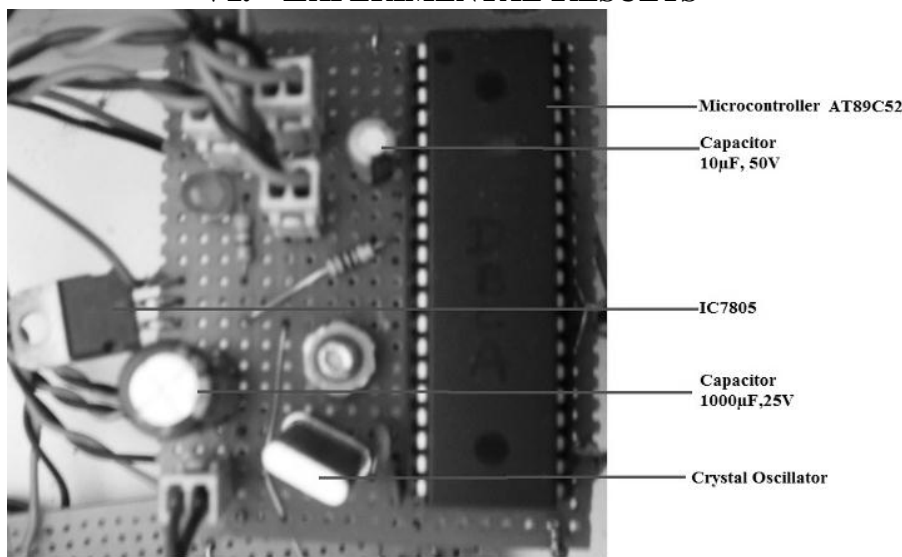

Fig.5 Hardware Setup of Microcontroller 


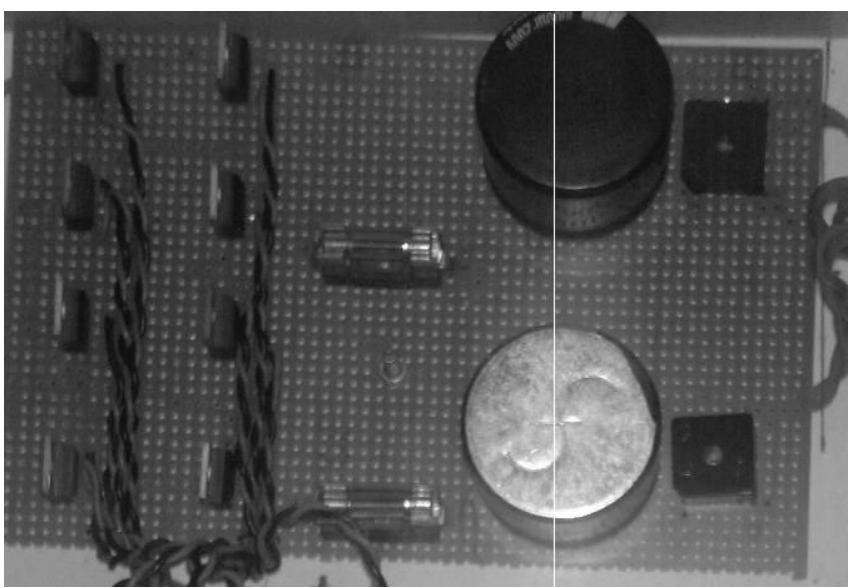

Fig.6 Hardware Setup of Single Phase Multilevel Inverter

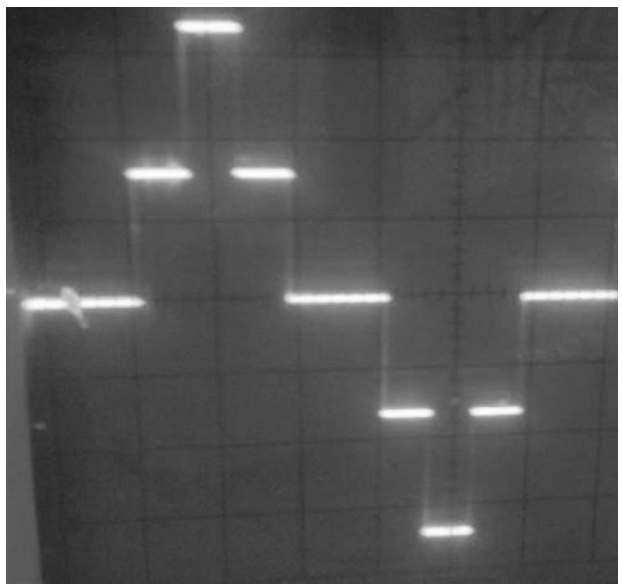

Fig.7 Single phase five level cascaded inverter output voltage

VII. CONCLUSION

The multilevel inverter is simulated and hardware setup is designed using microcontroller. Based on the hardware circuit it is concluded that the complexity of the hardware circuit is reduced using microcontroller when compared with traditional methods such as timers, comparators etc. The output voltage levels can be further increased by increasing the bridges and respective triggering signals from the microcontroller to reduce the total harmonic distortion.

\section{REFERENCES}

[1]. J. Rodriguez, J. S. Lai and F. Z. Peng, "Multilevel Inverters: Survey of Topologies, Controls, and Applications," IEEE Transactions on Industry Applications, vol. 49, no. 4, Aug. 2002, pp. 724-738.

[2]. J. S. Lai and F. Z. Peng, "Multilevel Converters-A new Breed of Power Converters," IEEE Trans. Ind. Applicat., vol.32,pp. 509-517, May/June 1996.

[3]. L. M. Tolbert, F. Z. Peng, and T. Habetler, "Multilevel Converters for Large Electric drives," IEEE Trans. Ind. Applicat.,vol.35,pp. 3644, Jan./Feb. 1999.

[4]. R. H. Baker and L. H. Bannister, "Electric Power Converter," U.S. Patent 3867 643, Feb. 1975.

[5]. Nabae, I. Takahashi, and H. Akagi, "A New Neutral-point Clamped PWM inverter," IEEE Trans. Ind. Applicat., vol. IA-17, pp. 518523, Sept./Oct. 1981.

[6]. P. C. Sen, "Principles of Electric Machines and Power Electronics", 2/E, John Wiley \& Sons, Inc, ISBN 0-471-02295-0, USA, 1997.

[7]. M. H. Rashid, "Power Electronics: Circuit, Devices and Applications", Second Edition, Prentice Hall of India, 1994.

[8]. Md. Abdul Latif, "Microcontroller based PWM inverter control," M. Engg. Project, Dept. of EEE, BUET, Dhaka, Bangladesh, July2006.

[9]. Atmel Corporation 2000, AT89C52 Microcontroller Datasheet.

[10]. B. Ismail, S. T. (November 28-29, 2006). Development of a Single Phase SPWM Microcontroller-Based Inverter. First International Power and Energy Conference PEC (p. 437). Putrajaya, Malaysia: IEEE. 